\title{
Object-Oriented Analysis of Very High-Resolution QuickBird Data for Mega City Research in Delhi/India
}

\author{
Susan Niebergall, Alexander Loew and Wolfram Mauser \\ Department of Geography, Section Geography \& Remote Sensing \\ University of Munich (LMU) \\ Munich, Germany \\ [s.niebergall,w.mauser]@iggf.geo.uni-muenchen.de,a.loew@lmu.de
}

\begin{abstract}
The 21st century is the century of the cities and of urbanisation. Mega cities in rapidly urbanising regions are hot spots of demographic and socio-economic dynamics. Their rapid growth results in uncontrolled processes of fragmentation which counteracts governance and steering . Due to the high dynamics of mega cities, the traditional methods such as statistical and regional analyses or fieldwork are limited to capture the urban process. New monitoring and planning methodologies are therefore required to provide tools to simplify planning processes in complex urban structures. Remote sensing provides the opportunity to monitor spatial patterns of urban structures with high spatial and temporal resolution. Very high-resolution remote sensing data from the QuickBird satellite are used to identify urban structures and dynamics within Delhi/India. The paper presents a first semi-automated, object-based classification approach which allows the distinction of different settlement types within the urban area. The method was developed for a representative data set within a selected test site and afterwards transferred to the whole test site as well as to a second region to prove the transferability and general validity of the methodology. The research is focused on the identification of "informal settlements" since these represent those characteristic municipal areas which are subject to particularly high dynamics, population density as well as marginalization. The developed methodology allows the recognition of similar settlement types within the urban area. In turn this outcome is compared with a pixel-based classification result to get an idea about the limits of conventional pixel-based classification methods. One of the project aims is the critical assessment of methods and the development of analytical tools. According to this fact the classification results were embedded in a framework for the determination of different socio-economic attributes (e.g. population density) within a certain settlement. This assumption is evaluated - in combination with quantitative and qualitative socio-economic information from about 800 questionnaires emanate from two intense field campaigns - in regard to placespecific infrastructure deficits. In addition, the methodology developed was tested on its transferability and general application. For this purpose other test sites in the Delhi area characterized by similar settlement structures were selected. This is understood to be a first step to the development of indicators which will help to identify and understand the different forms, actors and processes of vulnerability in mega cities.
\end{abstract}

\section{INTRODUCTION}

\section{A. Mega Cities}

In contrast to the last century where more people used to live in rural areas, at present more than half of the worlds population lives in urban settlements [1, 2]. By 20073.3 billion people will be living in cities. The total amount may even reach $60 \%$ by 2030 [2]. It is important to note that the majority of this population growth will occur in developing countries [3, 4, 5]. In this regard rapidly increasing urbanization induces many opportunities but also challenges and conflicts. In theory, as well as in popular opinion, (mega) cities offer the possibility for employment, education, services and the expectation of better health care. In fact, rapid and mostly unplanned urban growth is often associated with poverty, population demands, social inequality and environmental degradation that outstrip environmental service capacity, such as waste disposal and treatment, as well as drinking water and sanitation $[1,2]$. Recent research has shown that over 900 million people, or $31.6 \%$ of the world's urban population, are living under unacceptable conditions [6]. Hence, the identification of such "hot spots" of urban challenges is important in planning strategy [2]. Mega cities are more than just large agglomerations. They are also foci of global risk and major areas of demographic and socio-economic dynamics. Their rapid growth results in uncontrolled processes of fragmentation which counteracts governance and steering [7].

\section{B. Research Initiative}

Against the background of a German-Indian research project funded by German Research Foundation (DFG), the National Capitol Region (NCR) Delhi as a representative for a mega city with 12.5 million people living in this metropolitan region has been chosen as study site [12]. This research initiative has been launched in 2005 with the purpose to assess the vulnerability of people in the urban area of Delhi/India. The investigations hereby focus on the water supply and waste water situation within different parts of the metropolitan area [9]. In India, rapid urbanization is resulted due to the 
unprecedented population growth coupled with unplanned developmental activities. For further information about the research initiative please see [8].

\section{Application of Remote Sensing Data in Urban Environment}

To move towards sustainable urbanisation, it will be necessary to learn from recent experience and to develop new ideas and approaches to address a wide range of concerns. In connection with this remote sensing plays a crucial role. One of the challenges in the field of remote sensing is to provide the persons in charge with appropriate, up-to-date, city wide information in a very timely manner [5, 9]. New methodologies, tools as well as techniques and policies are required to monitor urban growth and alteration across the mega city and to forecast areas of risk - all within shorter timeframes and larger scale than previously accepted $[10,11]$. This will support a more proactive and sustainable urban planning and land management [5].

Remote sensing provides the opportunity to capture urban structures with high temporal and spatial resolution. The availability of commercial high-resolution satellite data at the sub-meter level (IKONOS, QuickBird) enabled the chance to identify recent small-scale land use structures and dynamics in mega cities. This is especially valuable in data poor environments [4]. With the results specific mega urban risk areas and living quarters of vulnerable population can be identified.

\section{STUDY AREA}

The study area is located within the National Capital Region (NCR) of Delhi (Figure 1). Delhi, with a population of over 12.5 million, is yet a growing mega city [12]. High rate of immigration and rapidly increasing population has increased the pressure on the existing infrastructure of the capital city of India. There are different kinds of residential quarters accommodating this tremendous inflow of people [13]. They range from the Jhuggi Jhompri clusters (slums and squatter settlements) to the planned colonies. About 50\% of the population is living in informal settlements and is plagued with inadequate infrastructural facilities and a number of water and wastewater related problems. Drinking water sources within the Delhi NCR are quite limited and depend to a large degree on agreements with neighbouring states [14].

Altogether, three different QuickBird images have been acquired where the heterogeneous nature of Delhi is best perceived and representative. Therefore the scenes represent for their part different development stages of Delhi:

- Central Delhi (North district) presents a mixed development trend and receives comparatively greater supply of water than the fringes,

- $\quad$ South Delhi (SW-District) is more disadvantageous in terms of water availability due to depletion and contamination of ground water,

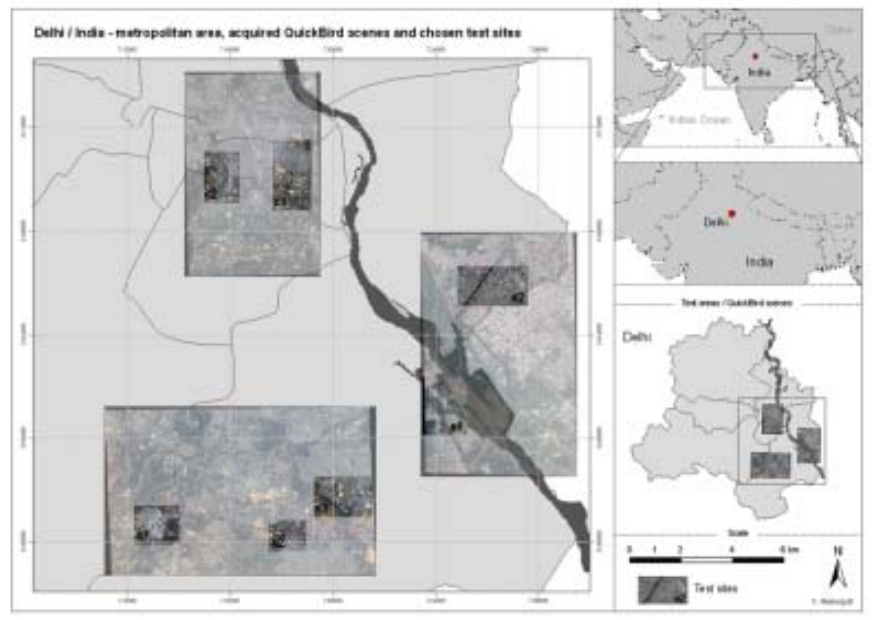

Figure 1. Delhi metropolitan area, acquired QuickBird scenes, and chosen test sites

- $\quad$ Trans Yamuna area (East District) representing a new housing complex and a sewage problem area (resettlement colonies).

Within the test areas, a total of seven single test sites have been chosen, based on prior suburb knowledge. The test sites show a high socio-economic gradient and large contrasts within short distances. In addition a "master" or training area inside test site S3 was selected. The chosen training area shows several forms of settlement structures beneath upper and middle class residential districts but also informal settlements. At a first stage the data analysis steps were tested at this area. The developed methodology was then transferred to the whole test site and other areas correspondingly.

\section{METHODS}

\section{A. Very High-Resolution Remote Sensing Data}

Remote sensing techniques have already shown their value in mapping urban areas and have been used as data sources for the analysis and modelling of urban growth and land use change $[15,16]$. Recently available very high-resolution satellite images (e.g. IKONOS or QuickBird) offer the potential to map urban areas at a spatial scale previously unattainable. This is especially valuable in data poor environments. Since the successful launch of Digital Globe's QuickBird satellite in October 2001 and the availability of the data, QuickBird imagery has quickly become a popular choice for large-scale mapping using very high-resolution satellites (Table I.).

QuickBird collects multi-spectral and panchromatic imagery concurrently, with resolutions of $2.44-2.88 \mathrm{~m}$ and $0.61-0.72 \mathrm{~m}$, respectively, depending upon the off-nadir viewing angle (0-25 degrees). In addition the sensor provides the widest nominal swath width and largest on board-storage of any current commercial satellite [17]. Due to this fact QuickBird data is used within the project to examine the potential of satellite images to identify vulnerable areas by their visible spatial structures and dynamics. 
2007 Urban Remote Sensing Joint Event

TABLE I. TECHNICAL FEATURES OF THE QUICKBIRD SENSOR

\begin{tabular}{lll}
\hline Orbit Information & Altitude & $450 \mathrm{~km}$ \\
& Inclination & $97.2^{\circ}$ (sun-synchron.) \\
& Equator crossing time & $10: 30 \mathrm{am}$ \\
& Nominal swath width & $16.5 \mathrm{~km}$ at nadir \\
& Revisit time & $1-3.5$ days \\
& Max. view angle & $30^{\circ}$ \\
\hline Resolution & Panchromatic & $\begin{array}{l}0.61 \mathrm{~m} \text { (nadir) }-0.72 \mathrm{~m} \\
\left(25^{\circ} \mathrm{off}-\mathrm{nadir}\right)\end{array}$ \\
& Multispectral & $2.44 \mathrm{~m}$ (nadir) $-2.88 \mathrm{~m}$ \\
& & $\left(25^{\circ} \mathrm{off}-\mathrm{nadir}\right)$ \\
\hline Spectral Coverage & Panchromatic & $450-900 \mathrm{~nm}$ \\
& Multispectral & \\
& Blue & $450-520 \mathrm{~nm}$ \\
& Green & $520-600 \mathrm{~nm}$ \\
& Red & $760-900 \mathrm{~nm}$ \\
\hline NIR &
\end{tabular}

\section{B. Field work}

As mentioned above an intense field campaign has been conducted in October 2005 to sample in situ information. The field campaign in Delhi aimed at the identification of striking objects detected in the QuickBird data (verification or detection itself), the mapping of different housing or settlement types, water related structures, as well as distinctive features or interesting points. Furthermore, to link them with specific structures or features in the satellite data, photographs were taken parallel to the ground mapping. Following the field work a basic evaluation of the field data and a visual interpretation of the QuickBird images were carried out [9].

\section{Data pre-processing}

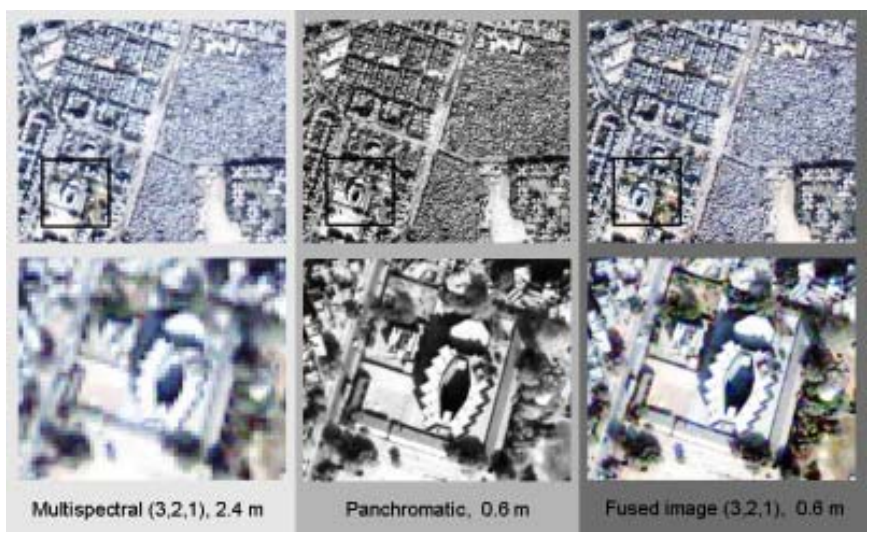

Figure 2. Principal Component (PC) pan-sharpening of the QuickBird data: (a) Multispectral, (b) Panchromatic, and (c) Fused image

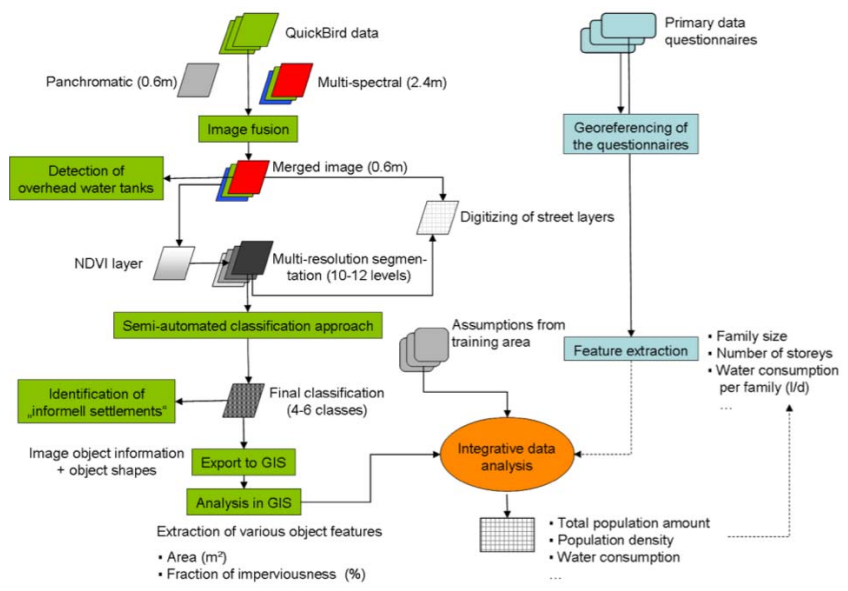

Figure 3. Flow chart of the implemented work steps

Prior to the classification and analysis of the satellite data some pre-processing was necessary. In order to benefit from high spatial resolution $(0.6 \mathrm{~m})$ simultaneously with multispectral information, a resolution merge was performed before analysing the images. On the basis of some tests with standard methods, a Principal Component (PC) pan-sharpening method with cubic convolution yielded the best results with respect to the radiometric and geometric characteristics of the original images (Figure 2) [17, 18].

\section{ANALYSIS AND RESULTS}

The work steps carried out shall be explained in the following. For a better understanding the workflow is displayed in Figure 3.

\section{A. Maximum Likelihood classification}

In order to have a first impression about the evaluation possibilities of the high-resolution satellite data and the comparison purposes, a supervised pixel-based classification was carried out. In this study, the maximum likelihood classifier (MLC) of ERDAS Imagine was utilized for the perpixel classification. Although MLC is based solely on spectral information of remote sensing data, it has been established as the standard statistical method for digital image classification because of its advantage in probability theory [20]. The pansharpened QuickBird data were classified into four basic classes - impervious surface, not impervious areas (bare soil), vegetation and shadow (Figure 4).

\section{B. Multi-resolution segmentation \& object-based image classification}

Compared to conventional pixel-based image processing, utilizing only the spectral response, image objects contain additional information like object texture, shape or relations to neighbours. Also due to the complexity of urban environment and changeable understanding of individuals an (semi-) automatic classification approach based on the application of object features seems to be very promising. To support this, the eCognition ${ }^{\mathrm{TM}}$ software by Definiens Imaging is investigated in this research [21]. 

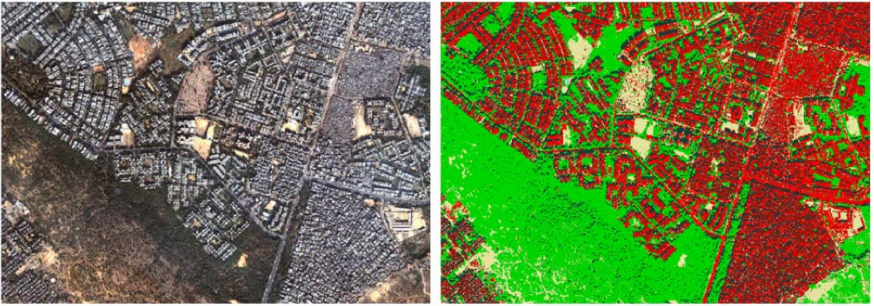

Impervious surface $\square$ Vegetation

Shadow $\square$ Not impervious surface

Figure 4. Fused QuickBird test site S3 $(3,2,1)$ vs. result of supervised, pixelbased classification

The first step in eCognition's object-based classification procedure is a multi-resolution segmentation technique which extracts image objects at modifiable scale parameters, single layer weights and the mixing of the homogeneity criterion concerning color and shape $[19,20]$.

The image segments (objects) have to be calculated on several hierarchical levels following an iterative "trial-anderror" process [22]. As an "ideal" object scale does not exist, objects of different levels of segmentation (spatial) and of different meanings (thematic) have to be combined. Figure 5 and 7 show a sequence of segmentation levels and the possibility of creating an arbitrary number of segmentation levels with segment sizes optimized in terms of the best fitting representation of the real world structures. For comparison purposes the segmentation was performed with and without (self-generated) street layers.

In a second step of the object-based classification the classes have to be named and the class "heritage" has to be defined. First a class hierarchy with only four classes was established. Based on this hierarchy and on the smallest objects (level 1) a preliminary classification was performed. The result shows a coarse land cover map for the training area in southern Delhi (Figure 6). Impervious and not
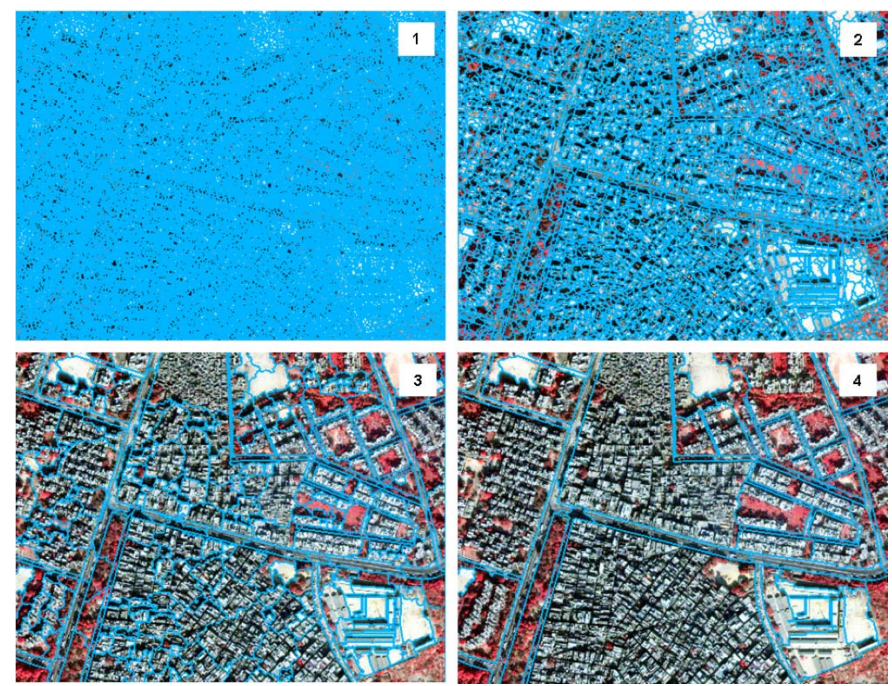

Figure 5. Results of "trial \& error" multi-resolution segmentation (varying parameters) for the subset of QuickBird test site S3 $(4,3,2)$
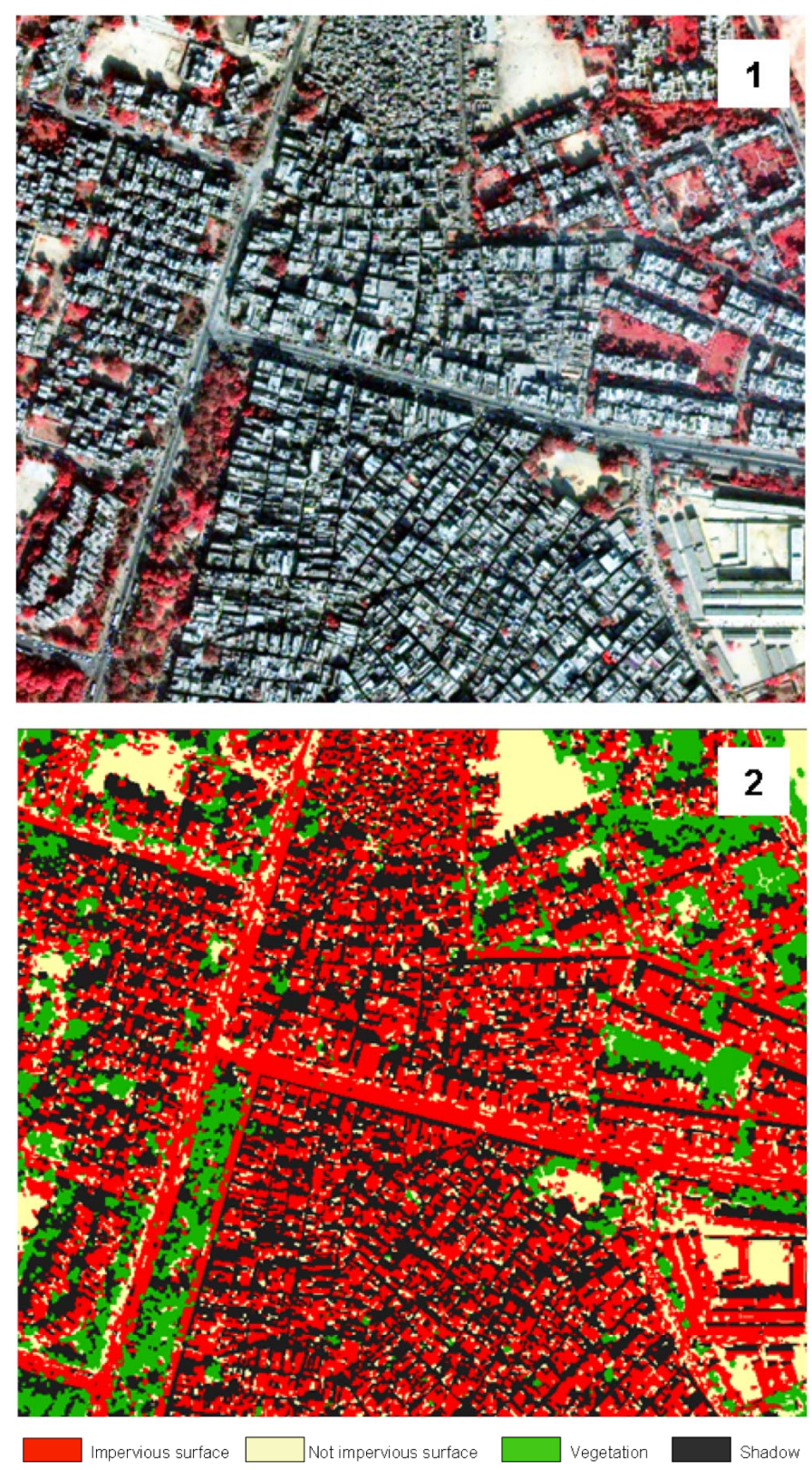

Figure 6. Object-based classification: (1) Subset of QuickBird test site 3, (2) Object-based classification (level1)

impervious areas, as well as vegetation and shadowed areas are displayed. In turn this outcome is compared with the above mentioned pixel-based classification result to get an idea about the limits of conventional pixel-based classification methods.

Since the first segmentation was connected to an effortful "trial-and-error" process, a second more robust and faster approach was developed. The knowledge derived from the first segmentation was introduced directly. Merely the scale parameter was changed systematically, the residual parameters (shape, smoothness etc.) remained constant. Moreover to the street layer, the NDVI was included as an additional band for the segmentation. 
Such as the first segmentation (Figure 4) it is a so called "bottom-up" approach. In this case the initial multi-resolution segmentation starts with generating small objects on the base level using a relatively small scale parameter.

All subsequently generated objects of the higher levels then act as super-objects of the base level objects which can be understood as aggregating the smaller objects to larger superobjects [23]. For results please see Figure 7. Particularly for the detection of informal settlements textural information is essential. Thus, a "bottom-up" approach with very fine segmentation on the base level and a coarse segmentation on the top level is a well suited approach. To take advantage of the textural information, objects on the top-level outline different settlement areas. Intermediary segmentation levels are necessary for the identification of medium scale objects (large buildings, parking lots etc.).

Starting with these segments a more effective classification method was developed and conducted. In this case instead of the smallest objects (level 1) a coarse one (level 8) was classified first ("top-down"). In this level you distinguished merely between the classes "streets" and "background". Sequentially in level 7 the class "very dense urban" was extracted and taken to the next smaller level. This hierarchical approach was used step by step to those levels in which the appropriate classes can be classified well. In order to avoid the time-consuming "trial-and-error" practice for seeking

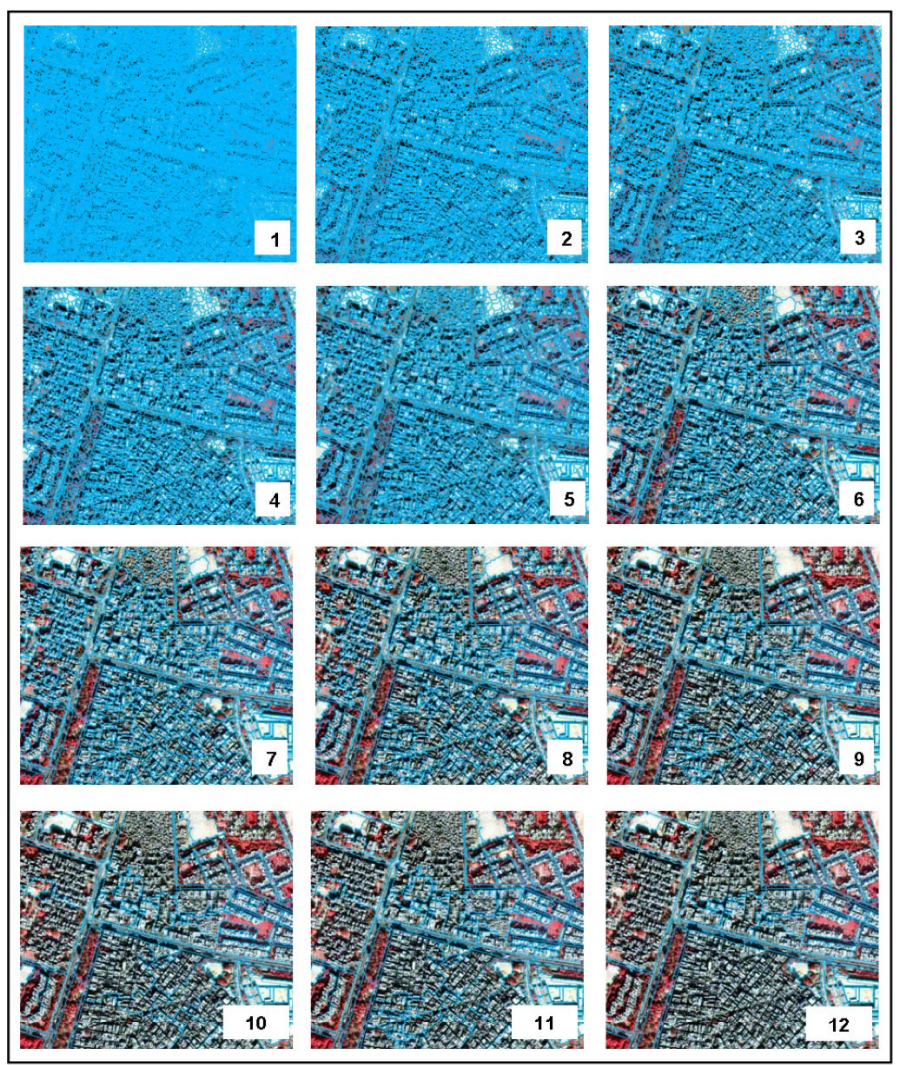

Figure 7. Merged QuickBird subset for test site S3: different multi-resolution image segmentation with varying scale parameter (constant parameter: shape [0.5], color [0.5], smoothness [0.3], compactness [0.7])

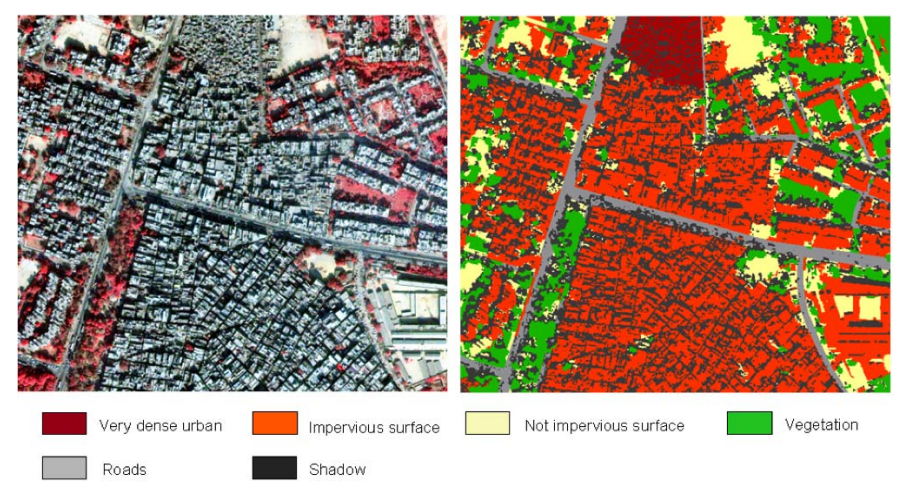

Figure 8. Training area of the fused QuickBird test site S3 $(4,3,2)$ vs. result of object-based classification

significant features for optimal class separation in object-based classification, an automatic feature extraction methodology, called SEaTH is used [24]. SEaTH calculates the SEperability and the corresponding Thresholds of object classes for any number of given features on the basis of a statistical approach. Final outcome is a classification with six land cover classes (Figure 8). Thereby the identification of different settlement types - regarding the building size and building density - is of special importance. It is therefore possible to detect "informal settlements" which are mega urban risk areas and thus potential residential zones of vulnerable population groups.

As mentioned above, the methodology developed was tested on its transferability and general validity. Therefore the whole test site S3 and test site S2 in the Delhi area characterised by similar settlement structures were analysed (Figures 9 and 10).
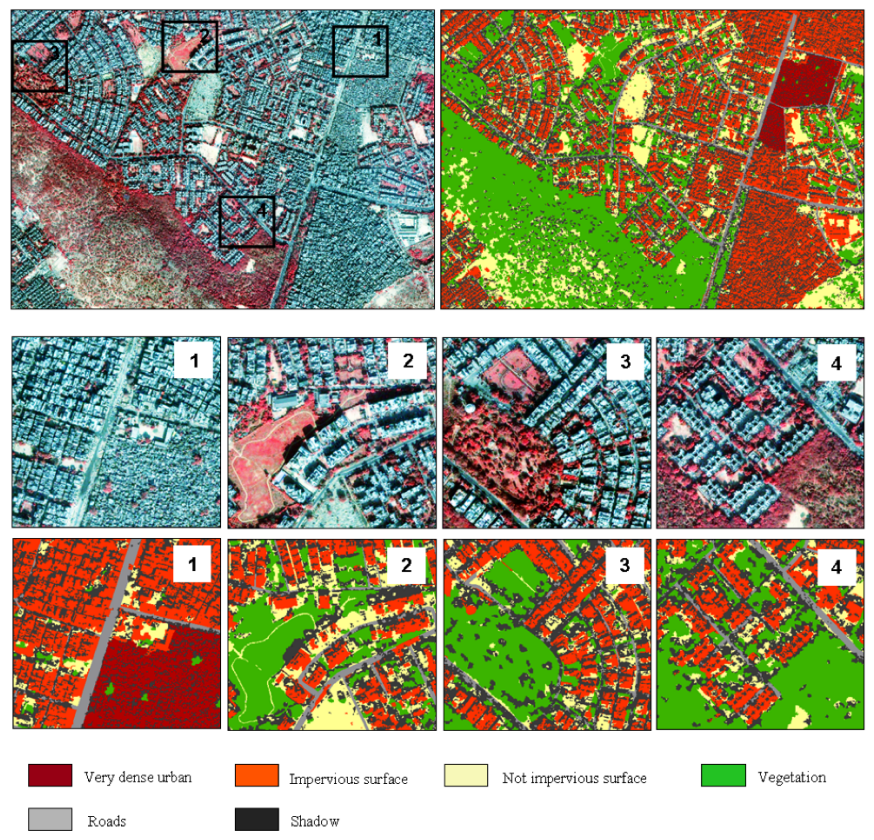

Figure 9. Fused QuickBird test site S3 $(4,3,2)$ vs. result of object-based image classification 


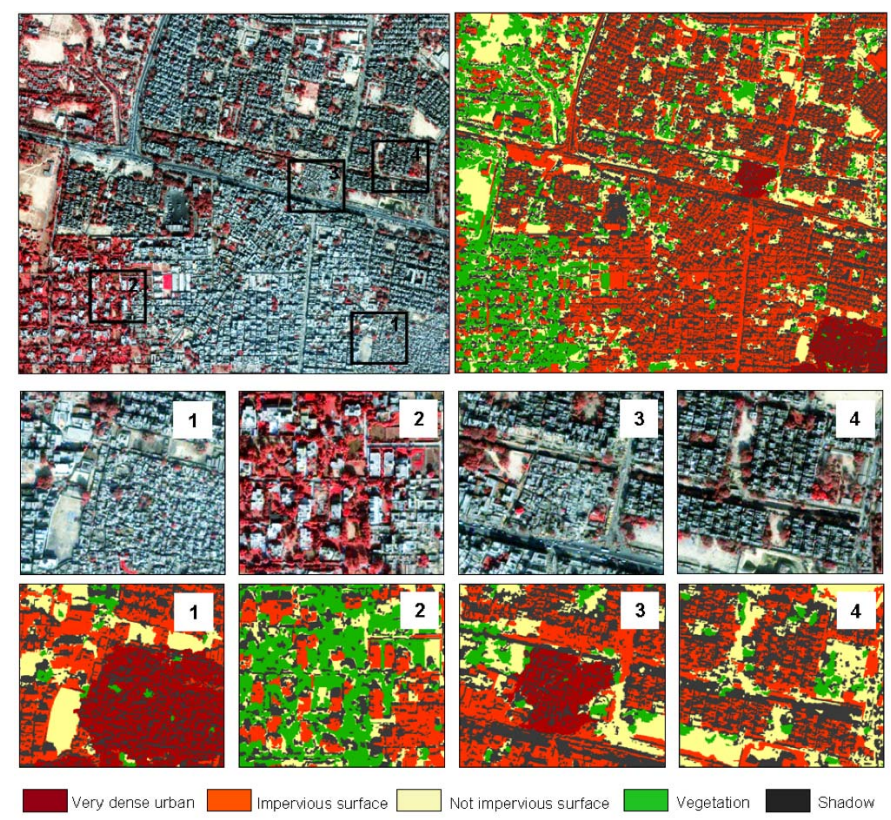

Figure 10. Fused QuickBird test site S2 $(4,3,2)$ vs. result of object-based image classification

\section{Integrative data analysis}

One of the project aims is the critical assessment of methods and the development of analytical tools. According to this fact the classification results were embedded in an analysis framework to determine different socio-economic attributes (population amount or population density) and to use that information to evaluate the water demand within a certain settlement area.

To use the information from the segments as well as the land cover information in the GIS, the shapes were exported in a following step. The exported shapes are characterized by shape features (image object information) only or additionally by class information (object shapes).

This information was used to calculate fractions for the respective classes in the GIS. In turn these results were implemented in a special evaluation methodology which shall be explained in the following more precisely.

The questions which are standing behind this methodology are the following:

- Due to the high dynamics of mega cities, the traditional methods such as statistical and regional analyses or fieldwork are limited to capture the urban process. Is it possible, that now high-resolution remote sensing data and the proper image processing techniques as well as GIS integration methodologies are going to be able to displace (compensate), support or supplement these traditional methods?
- Can a methodology be developed, which is able to determine the vulnerability within mega cities using an integrated approach, based on remote sensing information?

- Can socio-economic facts (e.g. population, population density, water consumption) be derived (in-) directly?

In connection with these questions an integrative approach was developed. The outline to this approach can be seen in Figure 11.

The integrative approach makes use of the primary database which was collected in questionnaires by the project partners within the framework of two intense field campaigns. These are used to characterize a given settlement type in terms of specific population and water related variables (e.g. family size, mean water consumption). In this place it should be mentioned that the questionnaires were georeferenced. Settlement characteristics (e.g. number of houses, house density) are estimated from the classified QuickBird data and used to derive spatial information about the population distribution. By combining the remote sensing derived data with the primary data, it is possible to provide maps of population densities or water consumption. To transfer the approach to unknown areas, where no primary data has been collected, assumptions have to be made for certain variables (e.g. family size, storeys) which might result in uncertainties in the estimated variables.

To evaluate the transferability of the approach, detailed examinations were at first carried out at a selected representative training area. The method was then applied to further comparable test sites, where questionnaires were also available for validation purposes, but which were not used in the analysis step. The evaluation of the results showed that the analysis based on the remote sensing data can be regarded as realistic. The results enable an identification of living quarters of vulnerable population. This is to be understood as a first step to the development of a transferable methodology for the identification and analysis of urban structures within mega cities.

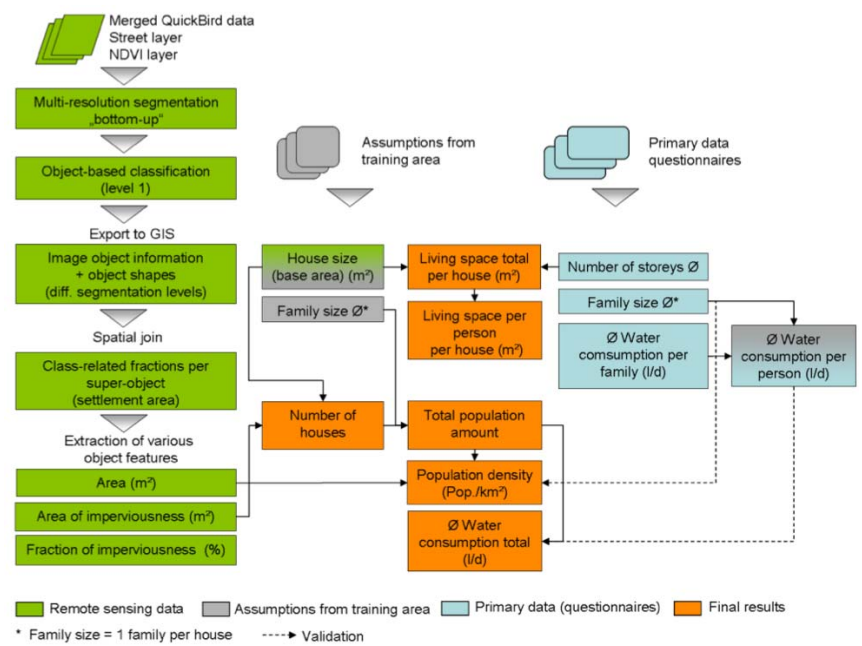

Figure 11. Integrative data analysis 


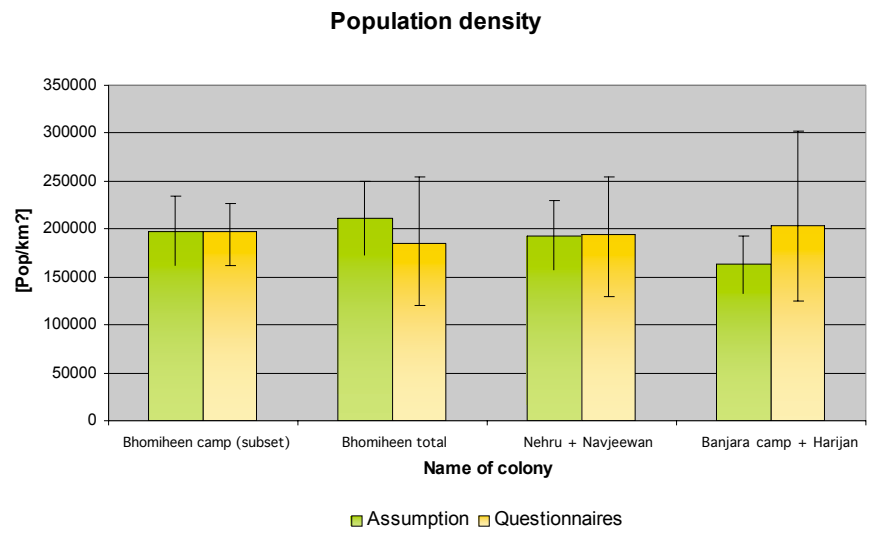

Total water consumption

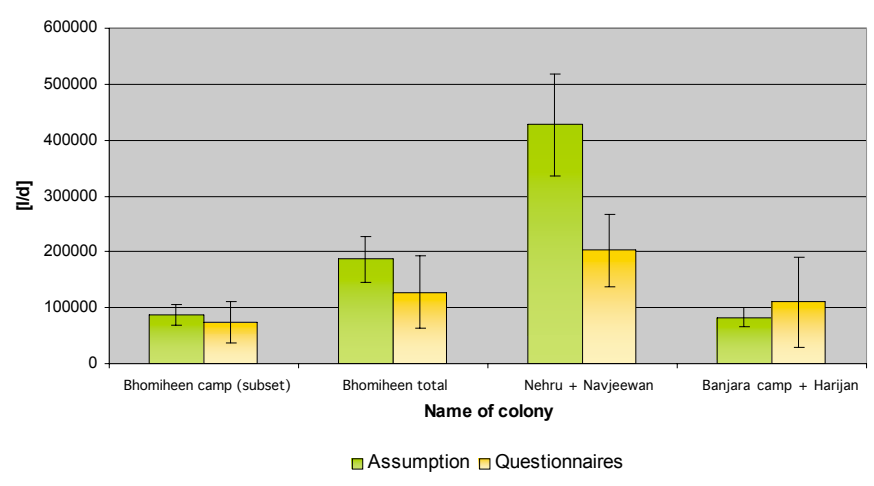

Figure 12. Results of the integrative data analysis

The achievements are promising. As shown in Figure 12 realistic data for „,population density“ or „,water consumption“ regarding a certain settlement area could successfully be pointed out. Only for the "total water consumption" of the Nehru and Navjeewan camp the values differ strongly from each other. The reason for this result are serious outliers in the interview statistic. Moreover, the simple standard deviation of the values is indicated into the graph.

\section{Change detection}

For demonstration of permanent change and development of the mega city Delhi current QuickBird data of 2006 has been acquired and is used for change detection purposes.

Figure 13 shows a subset of test site $\mathrm{C} 2$ in the centre of Delhi. In the image from 2002 there a Jhuggi Jhompri cluster is readily identifiable, whereas in the image of 2006 the informal settlement has disappeared completely. Responsible for this development is the government. This area has been vacated and the residents were resettled. Meanwhile, after the demolition of the settlement they have started to build up a shopping centre there. Hence, this area in Delhi is a good example to demonstrate the permanent change and development of a mega city.
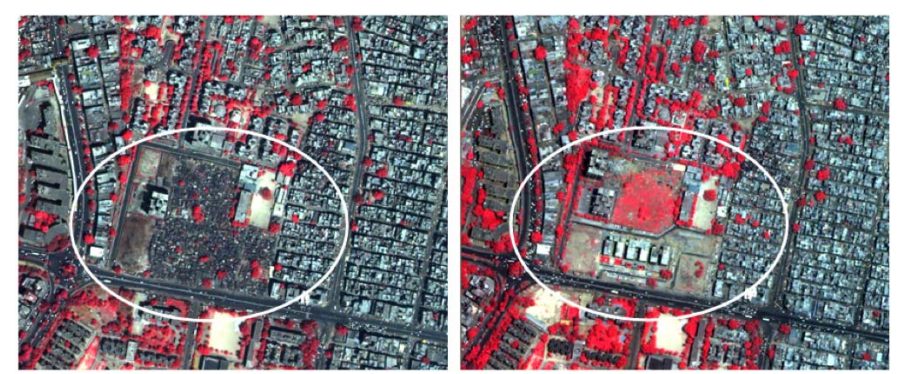

Figure 13. Image comparison of QuickBird data $(4,3,2)$ from the year 2002 (left) \& 2006 (right) (subset of test site C2)

\section{CONCLUSION}

A conclusion to be drawn from the study is the suitability of high-resolution QuickBird data for urban land use mapping, thus representing an alternative to traditional methods such as statistical and regional analyses or fieldwork. Amongst others the analysis enabled the mapping of different settlement types. It is therefore possible to detect "informal settlements" which are mega urban risk areas and thus potential residential zones of vulnerable population groups. Especially for these areas an immediate reaction of urban management seems to be necessary. Therefore appropriate, up-to-date, city wide information and new techniques has to be provide to the persons in charge in a very timely manner. This could support a more proactive and sustainable urban planning and land management - which increases the importance of remote sensing techniques. This method shall therefore be understood as a first step towards the development of stable indicators for the determination of vulnerability in mega cities like Delhi.

\section{ACKNOWLEDGMENTS}

The authors of the paper would like to thank the German Research Foundation (DFG) for funding this research initiative. Our thanks go also to our project partners from the University of Cologne for the questionnaire data. At least we would like to thank Dr. S. Nussbaum from Research Centre Juelich for the provision of the SEaTH-Algorithm.

\section{REFERENCES}

[1] M. Moore, P. Gould, and B. S. Keary, "Global urbanization and impact on Health,": International Journal of Hygiene and Environmental Health, vol. 206, pp. 269- 278, 2003.

[2] planetearth - Earth Science Society, "Megacities - our global urban future," Prospectus for a key theme of the International Year of Planet Earth, 16 pp., 2005.

[3] T. Kötter, "Risks and Opportunities of Urbanisation and Megacities, "Proceedings of the FIG Working Week: The Olympic Spirit of Surveying", 9 pp., 2004.

[4] J. Turkstra and M. Raithelhuber, "Urban slum monitoring”, 13 pp., 2004 http://gis.esri.com/library/userconf/proc04/docs/pap1667.pdf

[5] UN-Habitat, "Sustainable Urbanisation. Achieving Agenda 21“, Nairobi, Kenya, 20 pp., 2004.

[6] UN Habitat, "Slums of the World: The face of urban poverty in the new millennium?”, Nairobi, 90 pp., 2002.

[7] R. R. Rindfuss and P.C. Stern, "Linking remote sensing and social science: The need and the challenges," People and pixels. Linking remote sensing and social science, D. Liverman, E.F. Moran, R.R. 
Rindfuss and P.C. Stern, Eds. National Academy Press, Washington, D.C., pp 1-27, 1998.

[8] W. Mauser, F. Kraas, T. Krafft, A. Löw, S. Niebergall, V. Selbach., and R. Singh, "Vulnerability in Megacities: An Integrated Approach using High Resolution Satellite Data and Social Analysis," in Global change, Urbanisation and Health, W. Wuyi, T. Krafft, and F. Kraas, Eds. China Meteorological Press. Beijing, pp. 225-239, 2006.

[9] S. Niebergall, A. Loew, and W. Mauser, "Vulnerability in Megacities:Identification of Urban Structures in Delhi/India Using Very High-Resolution Remote Sensing Images", Proceedings of the 1st EARSeL Workshop of the SIG on Urban Remote Sensing: Challenges and solutions (CD), P. Hostert, S. Schiefer, and A. Damm, Eds. Humboldt-University of Berlin, 8 pp., 2-3 March 2006.

[10] R. Mc Laren, D. Coleman, and. S. Mayunga, "Sustainable Management of Mega Growth in Megacities," Proceedings of the FIG Working Week: From Pharaos to Geoinformatics, 15 pp., 2005.

[11] M. Herold, N. C. Goldstein, and K.C. Clarke, "The spatiotemporal form of urban growth: measurement, analysis and modelling," Remote Sensing of Environment, vol. 86, pp. 286-302, 2003.

[12] UN Population Division: World Urbanization Prospects. The 2001 Revision.

http://www.un.org/esa/population/publications/wup2001/WUP2001 repo rt.htm

[13] R. Singh, F. Kraas, T. Krafft, A. Loew, W. Mauser, S. Niebergall, and V. Selbach, "A New Approach to Analyse Water Related Vulnerability in Megacities: Case Study of Delhi,“ WHOCC Newsletter, 6 pp., 2007, in press..

[14] T. Krafft, T. Wolf, and S. Aggarwal, "A New Urban Penalty? Environmental and Health Risks in Delhi," Petermann's Geographische Mitteilungen, vol. 147(4), pp. 20-27, 2003.

[15] M. Herold, G. Menz, and K. C. Clark, "Remote sensing and urban growth models - demands and perspectives," Symposium on remote sensing of urban areas, Regensburg Germany, June 2001, Regensburger Geographiche Schriften, 35, 2001.

[16] T. Blaschke, S. Lang, E. Lorup, J. Strobl, and P. Zeil, „Object-oriented image processing in an integrated GIS / remote sensing environment and perspectives for environmental applications," Umweltinformation für Planung, Politik und Oeffentlichkeit / Environmental Information for
Planning, Politics and the Public, A. Cremers and K., Eds. Greve (Metropolis Verlag, Marburg), pp. 555-570, 2000.

[17] P. Cheng, T Toutin, and Y. Zhang, "QuickBird - Geometric Correction, Data Fusion, and Automatic DEM Extraction," Earth Observation Magazine (EOM), vol. 11 (4), pp.14-18, 2003.

[18] M. Ehlers, "Urban Remote Sensing: New Developments and Trends," Proceedings of the 5th International Symposium Remote Sensing of Urban Areas (URS 2005), Tempe, AZ, USA (CD proceedings), 6 pp, 2005.

[19] P. Hoffman, "Detecting Informal Settlements from IKONOS Image Data Using Methods of Object Oriented Image Analysis - An Example from Cape Town (South Africa)," 2nd International Symposium Remote Sensing of Urban Areas, Regensburg, Germany, 22-23 June 2001, supplemented CD-ROM for Regensburger Geographische Schriften, Heft 35, edited by Jürgens, C., pp. 107-118, 2001.

[20] F. Yuan and M.E. Bauer, "Mapping Impervious Surface Area Using High-Resolution Imagery: A Comparison of Object-Based and Per Pixel Classification," Proceedings of ASPRS 2006 Annual Conference, Reno, Nevada; May 1-5, 8 pp., 2006.

[21] M. Baatz., U. Benz, S. Dehghani, M. Heynen, A. Höltje, P. Hofmann, I. Lingenfelder, M. Mimler, M. Sohlbach, M. Weber, and G. Willhauck, "eCognition User Guide 3: Object Oriented Image Analysis," Definiens Imaging $\mathrm{GmbH}$, Munich, Germany, 2003.

[22] M. S. Moeller, W. L. Stefanov, and M. Netzband, "Characterizing Landcover Changes in Rapidly Growing Metropolitan Area Using Long Term Satellite Imagery," ASPRS Annual Conference Proceedings, Denver, Colorado, 9 pp., May 2004.

[23] P. Hofmann, "Detecting Informal Settlements from IKONOS Image Data Using Methods of Object Oriented Image Analysis - An Example from Cape Town (South Africa)," 2nd International Symposium Remote Sensing of Urban Areas, supplemented CD-ROM for Regensburger Geographische Schriften, Heft 35, C. Jürgens, Eds. Regensburg, Germany, pp. 107-118., 22-23 June 2001.

[24] S. Nussbaum, I. Niemeyer, and M. J. Canty, "SEaTH - A New Tool for Automated Feature Extraction in the Context of Object-Based Image Analysis," Proceedings of the 1st International Conference on Objectbased Image Analysis (OBIA 2006), S. Lang, T. Blaschke, and E. Schöpfer, Salzburg University, Austria, 6 pp., July 4-5 2006. 